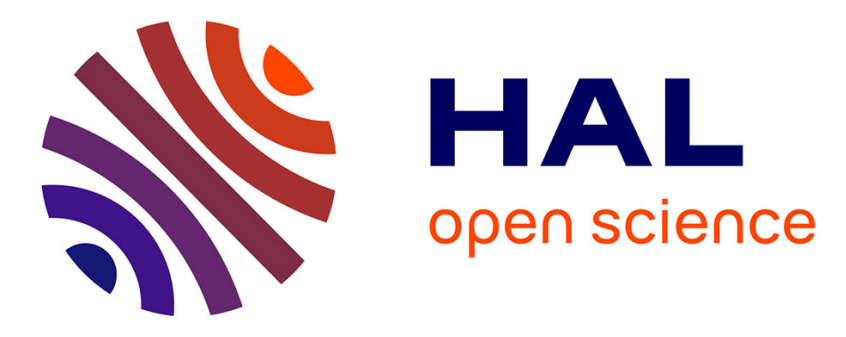

\title{
Sacroiliac joint morphologic changes from infancy to adulthood
}

Pierre Coudert, Roxanne Dube-Cyr, Kathia Chaumoitre, Olivier Gille, Jean-Marc Vital, Jean-Luc Jouve, Pierre-Jean Arnoux, Michel Panuel, Morgane Evin

\section{To cite this version:}

Pierre Coudert, Roxanne Dube-Cyr, Kathia Chaumoitre, Olivier Gille, Jean-Marc Vital, et al.. Sacroiliac joint morphologic changes from infancy to adulthood. The Spine Journal, 2019, 19 (10), pp17301738. hal-03256538

\section{HAL Id: hal-03256538 https://hal.science/hal-03256538}

Submitted on 10 Jun 2021

HAL is a multi-disciplinary open access archive for the deposit and dissemination of scientific research documents, whether they are published or not. The documents may come from teaching and research institutions in France or abroad, or from public or private research centers.
L'archive ouverte pluridisciplinaire HAL, est destinée au dépôt et à la diffusion de documents scientifiques de niveau recherche, publiés ou non, émanant des établissements d'enseignement et de recherche français ou étrangers, des laboratoires publics ou privés. 


\section{Sacroiliac Joint Morphological Changes from Infancy to Adulthood}

Pierre Coudert ${ }^{\mathrm{a}}$, Roxanne Dubé-Cyr ${ }^{\mathrm{d}, \mathrm{e}, \mathrm{f}}$, Kathia Chaumoitre ${ }^{\mathrm{b}, \mathrm{e}}$, Olivier Gille ${ }^{\mathrm{a}}$, Jean-Marc Vital ${ }^{\mathrm{a}}$, JeanLuc Jouve $^{\mathrm{c}}$, Pierre-Jean Arnoux ${ }^{\mathrm{e}, \mathrm{f}}$, Michel Panuel ${ }^{\mathrm{b}, \mathrm{e}}$, Morgane Evin e,f

\section{Affiliations :}

(a) Service d'Orthopédie traumatologie, Spine Unit 1 CHU de Bordeaux, Hôpital Pellegrin, France

(b) Aix Marseille Univ, CNRS, EFS, ADES, Marseille, France

(c) Service de chirurgie orthopédique et traumatologique pédiatrique, Hôpital de la Timone CHU de Marseille

(d) École Polytechnique de Montréal, Montréal, Canada

(e) Laboratoire de Biomécanique Appliquée, UMRT24 AMU/IFSTTAR, Marseille, France

(f) iLab-Spine - Laboratoire international en imagerie et biomécanique du Rachis, Marseille, France

Keywords : sacroiliac, growth, pelvic incidence, morphological analysis

\section{Corresponding author:}

Morgane EVIN

iLab Spine - Laboratoire de Biomécanique Appliquée

UMRT24 IFSTTAR - Aix Marseille Université

Faculté de Medecine secteur-Nord

51 Bd. P. Dramard 13015 Marseille

Phone number: (33)+4.91.65.87.61

Email : morgane.evin@ifsttar.fr

\section{Funding Disclosure Statement:}

This study was not the object of any specific funding sources and all authors report to not have any potential conflict of interest 


\section{Abstract}

3 Background context: Report of sacroiliac morphology changes during growth is limited in the literature and the

4 interest of such morphology and its consequence for surgery is increasing.

5 Purpose: Aims of this work are 1) to anatomically define the sacroiliac joint (SIJ), 2) to assess the influence of 6 growth on the sacroiliac morphology and the pelvic parameters.

7 Study design: Forty-nine young subjects from 6 months to 18 years old (y/o) and 20 adults aged from 18 to 50

8 y/o were selected from our institutional patient database.

9 Methods: They underwent a CT examination on a 128-MDCT (GE Healthcare Optima CT660). Transverse CT 10 image datasets were reconstructed, anonymized and segmented with ITK-SNAP. Landmarks and surfaces were selected and a SIJ orientation analysis was performed using costumed Python scripts.

Results: The subjects were divided into four groups: infants $(1.9 \pm 1 \mathrm{y} / \mathrm{o})$, children $(6.9 \pm 1.7 \mathrm{y} / \mathrm{o})$, adolescents $(13.7 \pm 1.8 \mathrm{y} / \mathrm{o})$ and adults $(27.3 \pm 5.6 \mathrm{y} / \mathrm{o})$. Differences between SIJ orientation were found significant between young subject groups for synovial sacrum SIJ orientation $(\mathrm{p}<0.001)$ and iliac total SIJ orientation $(\mathrm{p}=0.036)$. Both orientations of younger subjects were found significantly different from the adult group $(\mathrm{p}<0.035)$. SIJ synovial sacrum and iliac total orientations correlated significantly with age $(\mathrm{p}<0.03)$. All orientations correlated with pelvic incidence $(\mathrm{PI})(\mathrm{p}<0.04)$ except for synovial sacrum SIJ orientation $(\mathrm{p}=0.2)$. No gender or symmetrical differences were found significant in any group.

Conclusion: Morphological definition of the SIJ confirmed the independency of the gender during growth. Such results will be beneficial for the analysis and management of vertebral pathology. 
The sacroiliac joint (SIJ) is an important bilateral articulation of the pelvic girdle. It transfers weight from the upper body to the lower limbs via the spine and serves as a shock absorber. The SIJ is the most direct anatomical link between the pelvis (iliac bones) and the spine (sacrum). Such articulation has been described by anatomists as having a cartilaginous anterior part (synovial) and a fibroligamentar posterior synarthrosis. This unique configuration leads to its classification as a diarthrodial/synovial joint ${ }^{1}$.

It has limited mobility but a high stability due to different mechanisms of force-closure (muscles) and form-closure ${ }^{2}$. The form-closure mechanisms include the ligaments and the self-locking pelvic configuration caused by the wedged shape of the sacrum. Moreover, the articular surface on the sacrum is mostly concave while the iliac surface is mostly convex, adding to the stability of the SIJ.

Many changes were reported with aging, one of them being the formation of complementary ridges and grooves on the articular surfaces that increase friction ${ }^{2}$. Such changes are reported to first happen with locomotion ${ }^{3}$. On the iliac side, a groove (ventro-caudally to the iliac articular surface) is reported to appear in the second decade in women ${ }^{4,5}$. During growth, the correlation between pelvis widening and age is reported to be $0.333 \mathrm{~mm} / \mathrm{year}(\mathrm{p}<0.001)^{6}$. Even after skeletal maturity, the pelvic width was found to increase by $20 \mathrm{~mm}$. [ref Berger 2011] For the sacrum, three intersegmental fusions of the sacral vertebral segments (S1, S2, S3) occur: S1-S2 fusion occurs between 6 and 13 years old (y/o), while S2-S3 fusion occurs between 9 to $18 \mathrm{y} / \mathrm{o}^{7}$. Anthropology and archeo-biology have been defining SIJ and bridging for skeleton age assessment ${ }^{8,9}$. SIJ anatomy has been studied in evolution: neonatal subjects presented smaller angle of the sacral incidence when compared to adult subjects ${ }^{10}$. Such angle was found to be inversely correlated with sacro-acetabular distance (between middle of the sacral plate and middle of the bi-acetabular distance). Lateral and caudal to the first sacral vertebrae are the two main elevations that describe the SIJ, the first being the most prominent. There is a saddle shaped depression between the two elevations that appear during growth and changes with aging. Some gender differences have been reported. Men of 14 years of age and older have a larger articular bony tubercle in the middle of the auricular surface whereas women have a groove at the iliac SIJ surface. Current description of the joint is limited while description of the shape was reported without real quantitative measurements ${ }^{11}$.

Articular surface was reported to range from 10.7 to $18 \mathrm{~cm}^{2}$ depending on gender ${ }^{12-14}$. It is composed of hyaline and fibrocartilage, has a rough and coarse texture suggesting a functional adaptation ${ }^{15}$. The SIJ surface is divided into three parts as ventral, middle and dorsal (S1, S2, S3), with $40^{\circ}, 25^{\circ}$ and $10^{\circ}$ angle of the surfaces respectively ${ }^{16}$. While assessed by MRI, ossification of apophyses of the sacral wings show differences between genders in juvenile population ${ }^{17}$. Specificities of the auricular surface 
morphology contribute to the stability of the joint against shearing with a highest coefficient of friction compare to any diarthodial joint ${ }^{18}$. Mitchell et al. defined three horizontal axes within the SIJ (iliac and sacral) and a right and left diagonal ${ }^{19}$. Additionally, SIJ kinematics has been studied in-vitro and is mainly characterized by a sagittal rotation and an inferior translation of the sacrum (compared to the ilium) ${ }^{20}$.

A large portion of low back pain $\left(10\right.$ to $40 \%^{7}$ ) is reported to come from the SIJ ${ }^{21}$. Report of the SIJ morphology changes during growth in the literature is limited and the interest of such morphology and its consequence for surgery is increasing with the $310 \%$ increase of interventions per 100000 insured person from 2000 to $2011^{22}$. Stabilization of the SIJ is then becoming an economic and societal burden.

Bipedal gait differentiates human being from the rest of the mammalian and such bipedal gait is highly influenced by the SIJ anatomy ${ }^{10}$. Pelvic anatomy is defined in the spine adaptability (static and dynamic) to gait by three angles: the pelvic incidence (PI), sum of sacral slope and pelvic tilt. The PI changes with growth and has been reported to stagnate after the puberty. After puberty, PI is mostly fixed for a given patient ${ }^{23}$, although it can change slightly following surgery ${ }^{24}$. Predictors of lordosis have been previously described from sagittal alignment of the spine and pelvis ${ }^{25}$. Additionally, different posture types have been defined and correlated to pelvis, lordosis and kyphosis measurements $18,26,27$. However, such definition did not enable to explain completely the spine static and dynamic equilibrium and SIJ morphology has not be taken into account in such theories.

Hypothesis of this work is that the SIJ parameters are changing during growth (Figure 1), and that morphological definition of such joint will enable a better understanding of the spinal growth mechanism. The SIJ is believed to take part in the spinal equilibrium and insure the transmission of the loading from the spine to the lower limb. Thus, the orientation of the SIJ articular facets intervenes in biomechanical static and dynamic equilibrium of the spine. Aims of this work are to anatomically define the SIJ in terms of orientation and to assess the influence of the sacroiliac morphology on pelvic parameters.

\section{Methods}

\section{$\underline{\text { Population }}$}

We searched in our institutional database patients who had undergone CT examinations for traumatic or oncologic purposes including the pelvic area. We selected 69 subjects from 6 months to $50 \mathrm{y} / \mathrm{o}$ (49 
young: 7.4 $\pm 5.1 \mathrm{y} / \mathrm{o} ; 20$ adults: $27.3 \pm 5 . \mathrm{y} / \mathrm{o}$ ). The CT examinations were performed on 128-MDCT (GE Healthcare Optima CT660). The tube current was modulated according to the patient's body size and shape. In all cases, transverse CT image datasets were reconstructed with a section thickness inferior to $1 \mathrm{~mm}$ for the anatomic area from the 4th lumbar vertebra to the ischial tuberosity. The images were anonymized.

\section{Data processing}

Pelvic bones were segmented with the ITK-SNAP software ${ }^{28}$ using a threshold adapted to the patient's scan and a snake-based segmentation growing tool. Seven manually located landmarks and 10 surfaces were selected using Paraview (BSD License, NY 12065, USA) with definition of anterior superior iliac spine (ASIS), pubis, ischial spine, synovial SIJs (global and caudal) and femoral heads. Documentation for using Python in ParaView can be found in ParaView source documentation (https://www.paraview.org/documentation/).

\section{SIJ Angle Analysis}

ASIS landmarks were selected from the anterior view of the iliac bone. Two points were selected in the centre of the right and left pubic facets and the central pubic landmark was defined as the middle of those two points (Figure 2A). Ischium bone landmarks selection was set at the ischial tuberosity of each ischium. Those three landmarks were selected for left and right iliac crests (Figure 2A). A medium plane was computed based on the midpoints of those three pairs of landmarks (ASIS, pubic and ischium). Additionally, a landmark was set to the first sacral backbone (spinous process) to define an additional plane as the normal to the sacral plate in its midpoint crossing such landmark (Figure 2B).

Selection of the SIJ surfaces was performed in two parts: a total surface representing contact between the sacrum and the face of each iliac bone and a synovial surface defined as the partial higher surface (Figure 3). Since sacral vertebrae are not merged in younger subjects, two to three joints were selected on the sacral side. In those cases, the synovial surface was then defined as the sum of the second and third joints while total joint area was the sum of all surface areas. Planes were fitted on each surface. Additionally, sacral plate was selected as a surface. Computation of the fitted planes was performed using costumed Python scripts with numpy and matplotlib libraries (minimum least squares method as an example).

The midpoint (defined as the point with coordinates being the average of all point coordinates by axis) of the sacral plate was considered to be the center of reference. A plane was defined between the midpoint of the sacral plate and femoral heads in order to compute PI. 
1 The medium plane was considered as the reference plane and SIJ surfaces formed by points were used

2 to fit planes. Incidences between SIJ fitted planes and the reference plane were defined for each

3 selected surface. Incidence difference between synovial and total SIJ surfaces on both iliac bones and

4 sacrum were computed.

6 Areas were computed for each surface. Ratios between areas from synovial and total surfaces were 7 computed. Widths were defined at three locations of the joints and a cumulative width was provided as 8 the sum of all the widths (Figure 4).

$9 \quad$ Statistical analysis

10 Surface area differences between synovial and total surfaces were tested symmetrically to highlight 11 differences between left and right SIJ if any. Age groups were defined as different growth categories: 120 to $4 \mathrm{y} / \mathrm{o}$ (group 1), 4 to $10 \mathrm{y} / \mathrm{o}$ (group 2) and 10 to $18 \mathrm{y} / \mathrm{o}$ (group 3). Such definition enables to provide reference average? values with standard deviations. Correlations between SIJ parameters and age used to depict the continuous? changes of the parameters in aging and between SIJ parameters and PI were tested using R software ${ }^{29}$. Growth phases and group differences were analysed using an ANOVA and Wilcoxon test. Coefficient of variation (CV) was computed as the standard deviation of the differences between two measurements divided by the mean to assess reproducibility of the quantification of the morphology of SIJ on the 20 adults. 


\section{Results}

\section{Reproducibility of the methods}

CV of the four SIJ orientation angles varies from 14.9 to $31.5 \%$ (surface angles (SA) Sacrum Total: 29.7\%, synovial: $24.4 \%$; SA Iliac Total $31.5 \%$, synovial $14.9 \%$ ). Such reproducibility measurement concerned only the definition of landmarks and did not include the segmentation reproducibility or multiple-observer variability.

\section{SIJ angular orientation}

Average values for sacrum and iliac total and synovial angles with the reference plane were compared between the three growth categories (0-4 y/o /4-10 y/o old /10-18 y/o) and with the adult group (Table 1). In the 0 to $18 \mathrm{y} /$ o population, the synovial sacrum and total iliac SA were found to be influenced by the growth category ( $\mathrm{p}<0.001$ and $\mathrm{p}=0.036$ respectively). When compared to the adult population, differences were found significant for synovial sacrum and total iliac SA ( $\mathrm{p}=0.035$ and $\mathrm{p}=0.044$ ) but not for total sacrum and synovial iliac SA.

\section{Morphological analysis as areas and widths of the SIJ}

Areas and widths by growth category are reported in Table 2. Significant differences were found between young groups? for all values. When compared to adults, only synovial/total sacrum ratio was found not significant while all widths except cumulative widths were significantly different between young groups and adults $(\mathrm{p}<0.011)$.

\section{Changes during growth}

Correlations between the SIJ morphological parameters (angles, areas and widths) and age or PI are reported (Table 3 and Figure 5). Clear correlations with age were found for synovial sacrum SA $(\mathrm{p}<0.001)$ and total iliac SA $(\mathrm{p}=0.03)$. Similarly, areas and widths also strongly correlate with age $(\mathrm{p}<0.001)$.

\section{Pelvic incidence and correlation}

PI ranged in average per groups between 48.3 to $50.8^{\circ}$ for infants, children and adolescents and were significantly different from PI in adults $\left(39.9 \pm 13^{\circ}, \mathrm{p}=0.002\right.$-Table 1). PI correlates with total and synovial iliac SA and total sacrum SA ( $<<0.04)$ (Table 3$)$. It also correlates significantly with sacrum average width and synovial sacrum area $(\mathrm{p}<0.01)$. Correlation of PI with age was found significant $(\mathrm{p}=0.03)$.

\section{Gender differences and symmetry}


No significant differences between genders were found even when differentiating adults ( $\mathrm{p}$ ranged from 0.2 to 0.66 for angles and 0.09 to 0.33 for areas) from infants and adolescents adults (p ranged from 0.61 to 0.96 for angles and 0.12 to 0.3 for areas). SIJ angular orientations in infant, adolescent and adult groups differentiated by gender are reported in Table 1 . No symmetrical differences were found between right and left surface SIJ angles in the whole population (p: 0.1 to 0.79 ) or in subgroups (infants and adolescents: p: 0.1 to 0.79 , adults: p: 0.32 to 0.54 ).

\section{DISCUSSION}

This study improves the understanding of the morphological evolution of the pelvis during growth.

Existence of different spinal morphotypes has been shown ${ }^{26}$. Such morphology leads each individual to different static and dynamic properties. Accounting for such morphotypes in the physiopathology and management of spinal pathology (including surgical management) is common practice nowadays ${ }^{12}$. The pelvis, considered as the pelvic vertebrae, is closely linked to the spine and even indivisible in terms of biomechanics. Indeed, pelvic parameters (PI, pelvic tilt and sacral slope) determine spinal morphotypes and play a big role in the adaptation of the spine to pathological and mechanical situations (including especially pelvic retroversion ${ }^{8,24}$ ).

The SIJ is the focus of many research studies. The anatomical description and the biomechanical study of the motion of such structure have been studied at several years of life (childhood, growth, adult and aging) and is still discussed today ${ }^{11}$. Two studies of this large literature could be noticed as scan studies of the SIJ anatomy. Postacchini R. et al ${ }^{37}$ described the articular and extra-articular areas of the sacroiliac complex in adults. The bone anatomy was provided in order to differentiate the articular and extra-articular areas by CT scan as reported as more efficient for such differentiation than in MRI. Description of the sacroiliac surface in adults was mostly performed from their location relative to the sacral depression and SIJ space in coronal and axial planes. Such values are then difficult to compare to the results presented here. Regarding the paediatric population, Zejden A. and Jurik G. ${ }^{7}$ studied the bone anatomy of this area by tomodensimetry during growth (124 patients between 9 months and 18 $y / o)$ describing mainly the ossification kernel/core and the fusion of segments according with age and gender. Those two studies did not provide 3D-analysis of the morphology of the SIJ. To the best of our knowledge, we did not found any study reporting orientation of the articular sacroiliac surface, the evolution in those orientations with growth and its relationship to PI.

Reproducibility of the positioning of the landmarks and computation of the angles was assessed using CV. CV stayed under $35 \%$ for angular measurements which could be considered as reasonable and could be explained by the quality of the scan not enabling good segmentation and worsening landmark positioning. Intersegmental fusion assessment reliability was assessed in terms of agreement between two senior radiologists in ${ }^{4}$ and was of $4 \%$. However, they reported a classification rather than a 
continuous variable. Reports of similar measurements were not found in literature. However such results did not include the segmentation results as the methodology used for segmenting the SIJ was similar in all cases. Further shape analysis could be performed ${ }^{30}$.

In defining three sub-groups (0-4 y/o /4-10 y/o /10-18 y/o) and an adult group, significant changes during growth of the SIJ surface orientation have been shown. The angle of the SIJ surface regarding the reference plane to the sacral plate increases significantly with age and such result is more significant for synovial articular surfaces of the sacrum ( $\mathrm{p}<0.001$ for synovial sacrum SA and $\mathrm{p}=0.04$ for iliac total SA). This could be an adaptation to the weight gained during growth resulting in increased shear forces to the joint. Force resulting from gravitation could then be mostly transmitted through the synovial SA part in comparison with the dorsal part and thus increasing the form closure mechanism. This increase of angle reinforces the self-locking mechanism, therefore increasing the stability of the pelvic girdle. Differences were found significant between the 4-10 y/o group and 10-18 y/o group ( $p=0.022$ for synovial sacrum SA and almost significant 0.076 for total iliac SA) while no significant difference was found between the 0-4 y/o and 4-10 y/o groups. Growth of the spine has been reported to occur mostly between 0 and 5 years and during puberty which then leads to more detection of idiopathic scoliosis during puberty ${ }^{31,32}$. Similarly, we found that the SIJ morphology is significantly different between the 4 to 10 y/o group and the 10 to 18 y/o group which seems to correspond to a spine growth phase, although such results need to be confirmed with further investigation.

The synovial area localized in the antero-superior part of the articulation is more correlated with age than the fibro-ligamentar area localized in the postero-inferior part of the articulation (when synovial and total morphological changes are compared). Indeed, as shear forces increase with age, SIJ surfaces increase to insure stability and to limit stresses at the joint. As the morphology of the pelvis causes the synovial surface to be subjected to higher forces than the fibro-ligamentar area, this part of the joint seems to adapt more over time.

The results showed that there is no difference between gender in morphological changes during growth $(p>0.2)$. Such results agree with several studies showing the gender anatomical independency of such articulation particularly before puberty ${ }^{33}$ (no significant different in young and adult groups in our results). While pelvic dimensions have been reported to be larger in male around the $22^{\text {nd }}$ month with the difference decreasing later, consequences of such dimorphism on the SIJ articular surface could be a wider occupation of the sacral base by the fifth lumbar vertebra in male ${ }^{2}$. In our study, the size of the growth phase population may be too small to show significant changes in the orientation planes of the SIJ between genders.

Anatomical widths are also described in the results. It appeared that the changes in angles of the articular surfaces are associated with morphological changes of the structures. This highlights that the 
changes of the SIJ planes is part of a normal evolution and growth of the osteo-articular structures. This work provided a quantitative definition and reference values of the SIJ in growth.

PI has been shown to be a morphologic parameter, constant and invariable for a given patient. This pelvic parameter is established during growth and stabilizes definitely at the end of puberty. The PI has been shown to increase during growth, particularly during the first ten years ${ }^{9}$. However the mechanism influencing the value of such parameter are only partially known and understood nowadays. The pelvis, as an osteoarticular structure, changes during growth. To the best of our knowledge, few studies have shown the link between morphological growth of the pelvic ring and the establishment of pelvic parameters. In 2014, the works of Schlösser, et al. ${ }^{34}$ reported a lordosis development during a morphological growth and correlation of such parameters with PI. The relationship described between the pelvis and PI makes us think that the morphological evolution of the pelvis plays a crucial part in the definition? of the pelvic parameters and thus, through biomechanical relationship, of the spinal morphotype. In this work, a significant correlation between orientation of the SIJ surface compared to orthogonal reference plane and the value of the PI is reported. Such results are significant for total sacrum SA, total iliac SA and synovial iliac SA (Table 3). Thus, the more the SIJ articular plane opens externally, the higher the pelvic incidence $(p<0.04, R$ ranged between 0.2 and 0.44 ). This is in line with the conclusions from Abola et al. ${ }^{35}$ that PI had an influence on the SIJ. They reported that a higher PI was associated with a more angulated and curved sacrum and a more linear SIJ in the sagittal plane. Our study shows that it also has an effect on the orientation of the SIJ in the horizontal plane, through PI correlation with total sacrum and iliac SA. The synovial surface area of the sacrum is also positively correlated with PI. Pelvis with higher PI tend to have a more horizontal sacrum, potentially further increasing forces on the synovial area of the joint, thus leading to an increased surface area and average width of the synovial sacrum part.

Statistical power of our study is however limited by the available number of patients as well as by the difficulties of the lengthy post-processing, including segmentation and measurements. However, such results reinforce the hypothesis that the morphological changes of the articular surface of the SIJ is related to the definition of pelvic parameters specific to the individual and thus to the spinal morphotypes.

Mac-Thiong et al. ${ }^{36}$ showed the interaction forces between the different segments in the pelvic-spinal sagittal equilibrium in the paediatric population. This work enables to include, downstream to such mechanism, the significant correlation between the articular surface SIJ orientation and the PI (Figure $6)$. 


\section{CONCLUSIONS}

2 The results of this work help us to investigate the constitutive mechanisms of pelvic and spinal 3 morphotypes as well as the relation between pelvic and vertebral structures. They come within the 4 scope of the human's growth process by the acquisition of the biped standing in the development.

5 They also show no difference in the SIJ angular orientation between genders.

6 Thus, they will be beneficial to the analysis and management of spinopelvic pathology (including

7 distortion) of the infant, child and adolescent, at ages when the maturity of the pelvic-spinal base is not 8 yet definitive.

9 It is then necessary and interesting to further study the biomechanical and morphological analysis on a higher number of subjects, and integrate the analysis of the spinal curves (e.g. lumbar lordosis, thoracic kyphosis), together with pelvic parameters (pelvic incidence, pelvic tilt and sacral slope) and spinal morphotype of each patient. 


\section{REFERENCES}

1. Dall BE, Eden SV, Rahl MD (eds). Surgery for the Painful, Dysfunctional Sacroiliac Joint: A Clinical Guide. Springer International Publishing. Available at https://www.springer.com/la/book/9783319107257. 2015, Accessed April 8, 2019.

2. Vleeming A, Schuenke MD, Masi AT, et al. The sacroiliac joint: an overview of its anatomy, function and potential clinical implications. J Anat 2012;221:537-67.

3. Solonen KA. The sacroiliac joint in the light of anatomical, roentgenological and clinical studies. Acta Orthop Scand Suppl 1957;27:1-127.

4. Brooke R. The Sacro-Iliac Joint. J Anat 1924;58:299-305.

5. Vleeming A, Van Wingerden JP, Dijkstra PF, et al. Mobility in the sacroiliac joints in the elderly: a kinematic and radiological study. Clin Biomech Bristol Avon 1992;7:170-6.

6. Berger AA, May R, Renner JB, et al. Surprising evidence of pelvic growth (widening) after skeletal maturity. J Orthop Res Off Publ Orthop Res Soc 2011;29:1719-23.

7. Zejden A, Jurik AG. Anatomy of the sacroiliac joints in children and adolescents by computed tomography. Pediatr Rheumatol Online J;15. Epub ahead of print November 25, 2017. DOI: 10.1186/s12969-017-0210-0.

8. Boulay C, Tardieu C, Hecquet J, et al. Sagittal alignment of spine and pelvis regulated by pelvic incidence: standard values and prediction of lordosis. Eur Spine J Off Publ Eur Spine Soc Eur Spinal Deform Soc Eur Sect Cerv Spine Res Soc 2006;15:415-22.

9. Kendall HO, Kendall FP, Wadsworth GE. Muscles, Testing and Function. Am J Phys Med Rehabil 1973;52:43.

10. Tardieu C, Bonneau N, Hecquet J, et al. How is sagittal balance acquired during bipedal gait acquisition? Comparison of neonatal and adult pelves in three dimensions. Evolutionary implications. J Hum Evol 2013;65:209-22.

11. Hens SM, Godde K. Auricular Surface Aging: Comparing Two Methods that Assess Morphological Change in the Ilium with Bayesian Analyses. J Forensic Sci 2016;61:S30-8.

12. Miller J a. A, Schultz AB, Andersson GBJ. Load-displacement behavior of sacroiliac joints. $J$ Orthop Res 1987;5:92-101.

\section{Sashin D. A CRITICAL ANALYSIS OF THE ANATOMY AND THE PATHOLOGIC} CHANGES OF THE SACRO-ILIAC JOINTS. JBJS 1930;12:891.

14. Ebraheim NA, Biyani A. Percutaneous computed tomographic stabilization of the pathologic sacroiliac joint. Clin Orthop 2003;252-5.

15. Bowen V, Cassidy JD. Macroscopic and microscopic anatomy of the sacroiliac joint from embryonic life until the eighth decade. Spine 1981;6:620-8.

16. Dijkstra PF, Vleeming A, Stoeckart R. Complex motion tomography of the sacroiliac joint. An anatomical and roentgenological study. ROFO Fortschr Geb Rontgenstr Nuklearmed 1989;150:635-42. 
17. Bollow M, Braun J, Kannenberg J, et al. Normal morphology of sacroiliac joints in children: magnetic resonance studies related to age and sex. Skeletal Radiol 1997;26:697-704.

18. Weisl H. The movements of the sacroiliac joint. Acta Anat (Basel) 1955;23:80-91.

19. Mitchell FL, Moran PS, Pruzzo NA, et al. An evaluation and treatment manual of osteopathic muscle energy procedures. 1st ed. Valley Park, Mo. : Mitchell, Moran and Pruzzo, Associates. Available at https://trove.nla.gov.au/version/45422031. 1979, Accessed June 5, 2018.

20. Hammer N, Scholze M, Kibsgård T, et al. Physiological in vitro sacroiliac joint motion: a study on three-dimensional posterior pelvic ring kinematics. J Anat 2019;234:346-58.

21. Sembrano JN, Polly DW. How Often Is Low Back Pain Not Coming From the Back? Spine;34. Epub ahead of print January 1, 2009. DOI: 10.1097/BRS.0b013e31818b8882.

22. Gras F, Hillmann S, Rausch S, et al. Biomorphometric Analysis of Ilio-Sacro-Iliacal Corridors for an Intra-Osseous Implant to Fix Posterior Pelvic Ring Fractures. J Orthop Res 2015;33:25460 .

23. Le Huec JC, Aunoble S, Philippe L, et al. Pelvic parameters: origin and significance. Eur Spine J 2011;20:564-71.

24. Place HM, Hayes AM, Huebner SB, et al. Pelvic incidence: a fixed value or can you change it? Spine J. Epub ahead of print June 2017. DOI: 10.1016/j.spinee.2017.06.037.

25. Alderink GJ. The sacroiliac joint: review of anatomy, mechanics, and function. J Orthop Sports Phys Ther 1991;13:71-84.

26. Roussouly P, Gollogly S, Berthonnaud E, et al. Classification of the normal variation in the sagittal alignment of the human lumbar spine and pelvis in the standing position. Spine 2005;30:346-53.

27. Laouissat F, Sebaaly A, Gehrchen M, et al. Classification of normal sagittal spine alignment: refounding the Roussouly classification. Eur Spine J Off Publ Eur Spine Soc Eur Spinal Deform Soc Eur Sect Cerv Spine Res Soc 2018;27:2002-11.

28. Yushkevich PA, Piven J, Hazlett HC, et al. User-guided 3D active contour segmentation of anatomical structures: significantly improved efficiency and reliability. NeuroImage 2006;31:1116-28.

29. R Core Team R: A Language and Environment for Statistical Computing. R Foundation for Statistical Computing. 2013.

30. Márquez EJ, Cabeen R, Woods RP, et al. The Measurement of Local Variation in Shape. Evol Biol 2012;39:419-39.

31. DiMeglio A, Dimeglio A, Canavese F, et al. Growth and adolescent idiopathic scoliosis: when and how much? J Pediatr Orthop 2011;31:S28-36.

32. Dimeglio A, Canavese F. The growing spine: how spinal deformities influence normal spine and thoracic cage growth. Eur Spine J Off Publ Eur Spine Soc Eur Spinal Deform Soc Eur Sect Cerv Spine Res Soc 2012;21:64-70.

33. Klein P, Sommerfeld P. Biomécanique des membres inférieurs: bases et concepts, bassin, membres inférieurs. Elsevier Masson; 2008. 
34. Schlösser TPC, Janssen MMA, Vrtovec T, et al. Evolution of the ischio-iliac lordosis during natural growth and its relation with the pelvic incidence. Eur Spine J 2014;23:1433-41.

35. Abola MV, Teplensky JR, Cooperman DR, et al. Pelvic Incidence Is Associated With Sacral Curvature, Sacroiliac Joint Angulation, And Sacral Ala Width. Spine. Epub ahead of print April 12, 2018. DOI: 10.1097/BRS.0000000000002679.

36. Mac-Thiong JM, Wang Z, de Guise JA, et al. Postural model of sagittal spino-pelvic alignment and its relevance for lumbosacral developmental spondylolisthesis. Spine Phila Pa 1976 2008;33:2316-25.

37. Postacchini R, Trasimeni G, Ripani F, et al. Morphometric anatomical and CT study of the human adult sacroiliac region. Surg Radiol Anat SRA 2017;39:85-94. 
3 Figure 1. Illustration of the hypothesis: orientation of the SIJ is changing during growth and is

4 correlated to the pelvic incidence's evolution.

5 Figure 2. SIJ Angular Analysis: A) SIJ selections, B) central plane in dark grey (based on landmarks

6 on sacroiliac crests, pubis and ischium), sacrum plate fitted plane in light grey and pelvic incidence

7 plane in transparent light green (based on midpoint of sacrum plate and centres of femoral heads); C)

8 fitted plane on sacral SIJ on a young subject (2.4 y/o, female).

$9 \quad$ Figure 3. Illustration of the different joint surfaces of the SIJ analysed in our study

Figure 4. Morphological analysis of the SIJ: A) widths defined on each sacral and iliac SIJ, B) Landmarks definition.

Figure 5. SIJ correlations with age and PI.

Figure 6. Schematic relationship between spine parameters according to ${ }^{36}$ and with the SIJ addition.

\section{TABLES LEGEND}

Table 1. Normal value in different growth categories (0 to $4 \mathrm{y} / \mathrm{o}, 4$ to $10 \mathrm{y} / \mathrm{o}$ and 10 to $18 \mathrm{y} / \mathrm{o}$ ), in adults and in the whole population. Significativity: *: $p<0.05, * *: p<0.005, * * *: p<0.001$

Table 2. Shape Analysis of the SIJ including area: widths and spline analysis. Significativity: *: $\mathrm{p}<0.05 . * *: \mathrm{p}<0.005 . * * *: \mathrm{p}<0.001$

Table 3. Pearson correlations between SIJ characteristics and age or PI. 
2 Figure 1. Illustration of the hypothesis: orientation of the SIJ is changing during growth and is 3 correlated to the pelvic incidence's evolution.

\section{SIJ orientation}

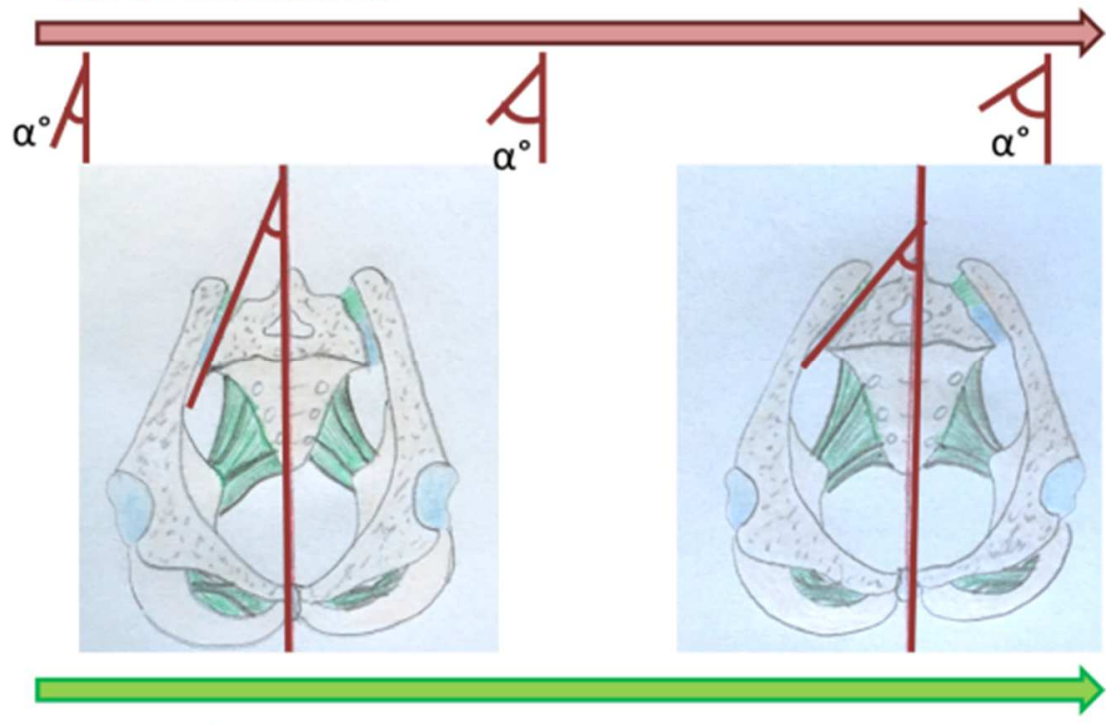

Growth

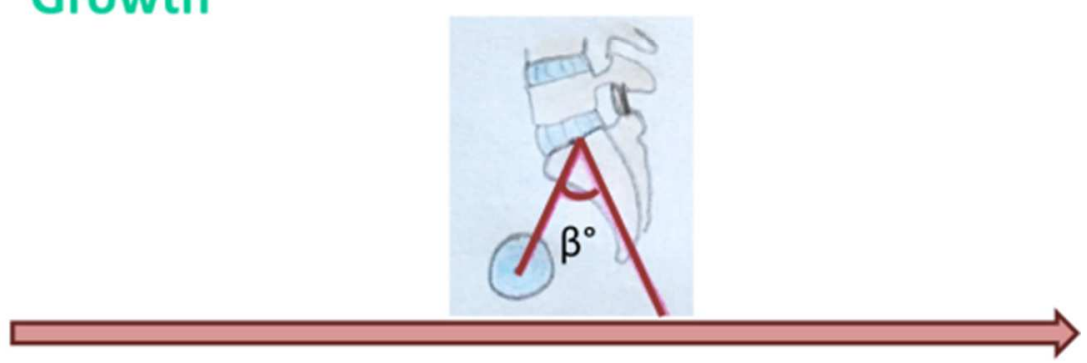

Pelvis incidence (PI) 
1 Figure 2. SIJ Angular Analysis: A) SIJ selections, B) central plane in dark grey (based on landmarks 2 on sacroiliac crests, pubis and ischium), sacrum plate fitted plane in light grey and pelvic incidence 3 plane in transparent light green (based on midpoint of sacrum plate and centres of femoral heads); C)

4 fitted plane on sacral SIJ on a young subject (2.4 y/o, female).

5

6

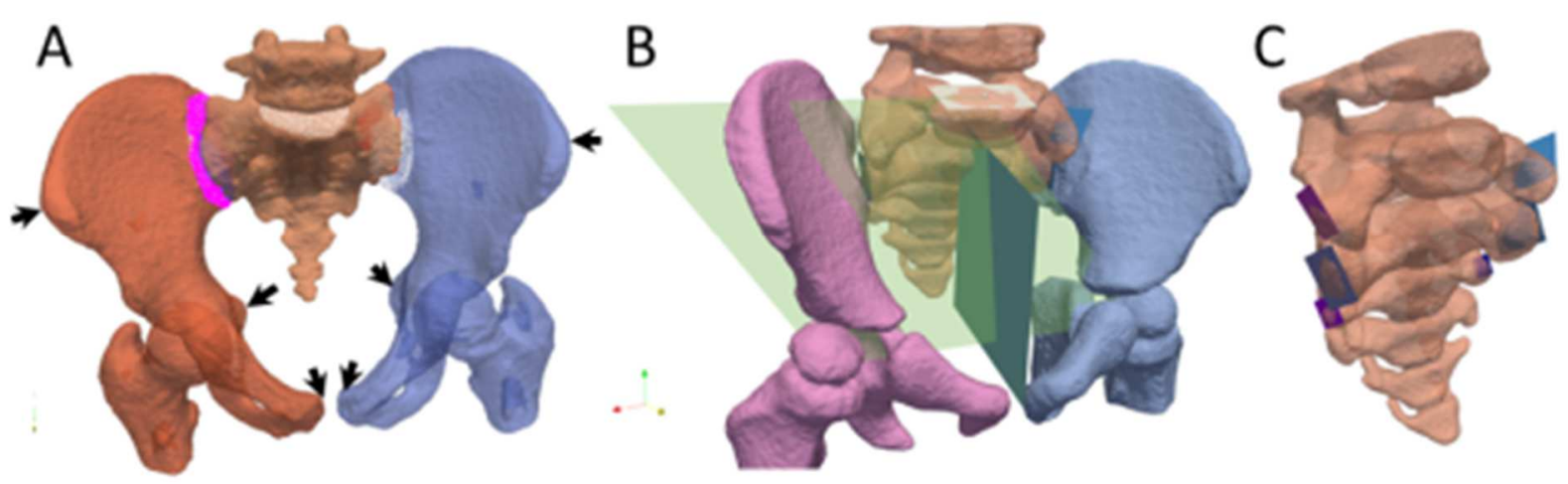

7 
1 Figure 3. Illustration of the different joint surfaces of the SIJ analysed in our study

2

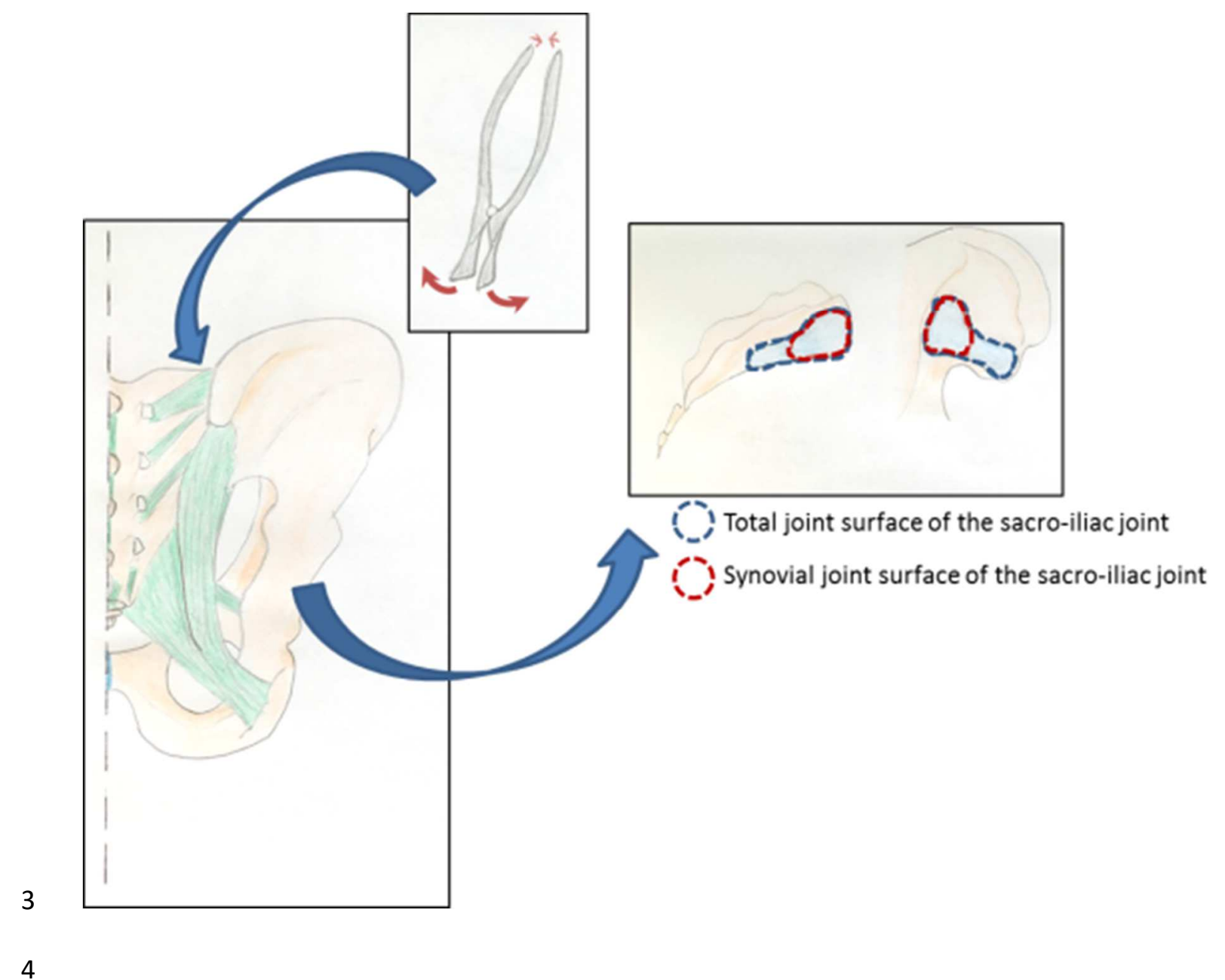


2 Figure 4. Morphological analysis of the SIJ: A) widths defined on each sacral and iliac SIJ, B)

3 Landmarks definition.

4

5

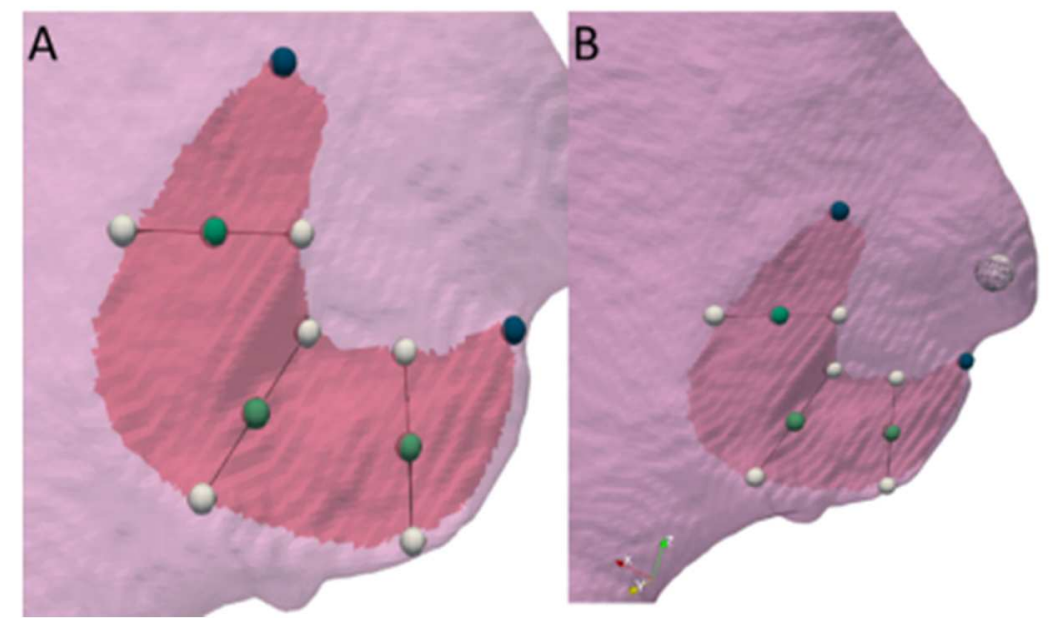

6 
1 Figure 5. SIJ correlations with age and PI.

2
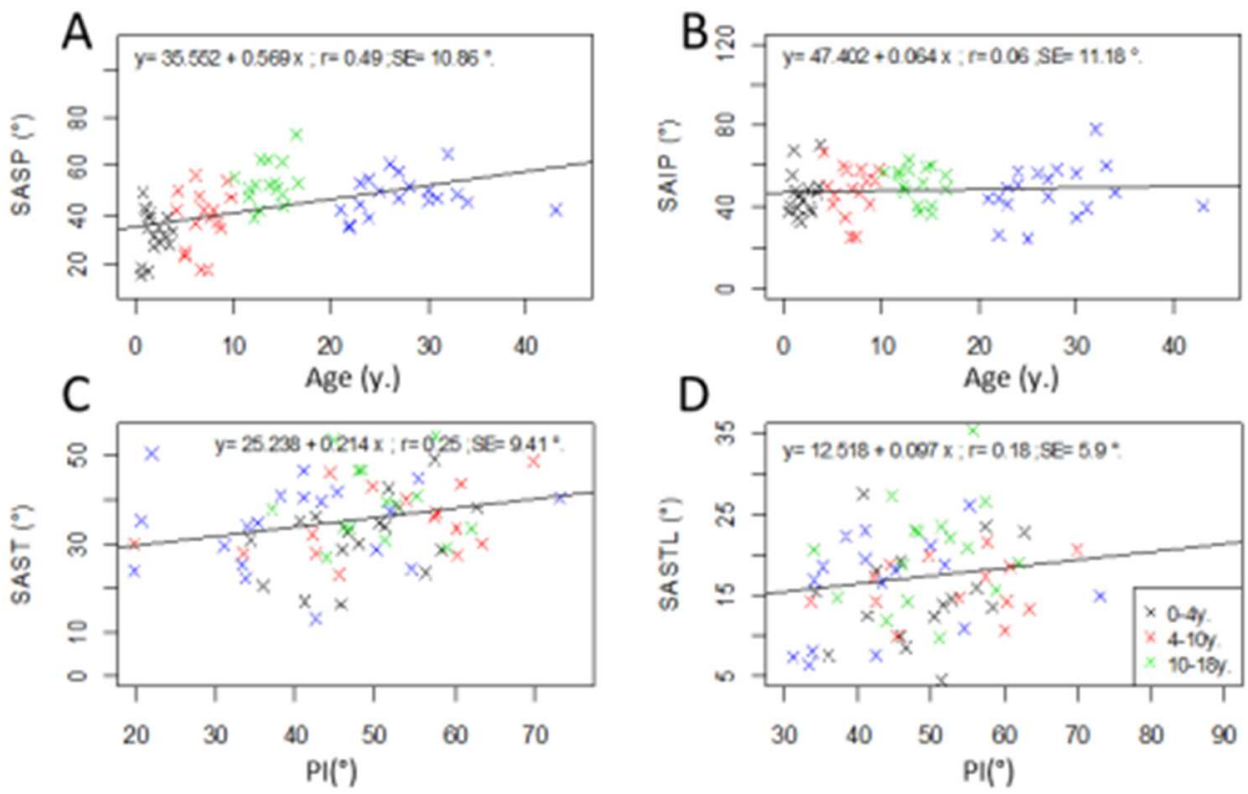

3

4 
1 Figure 6. Schematic relationship between spine parameters according to ${ }^{28}$ and with the SIJ addition.

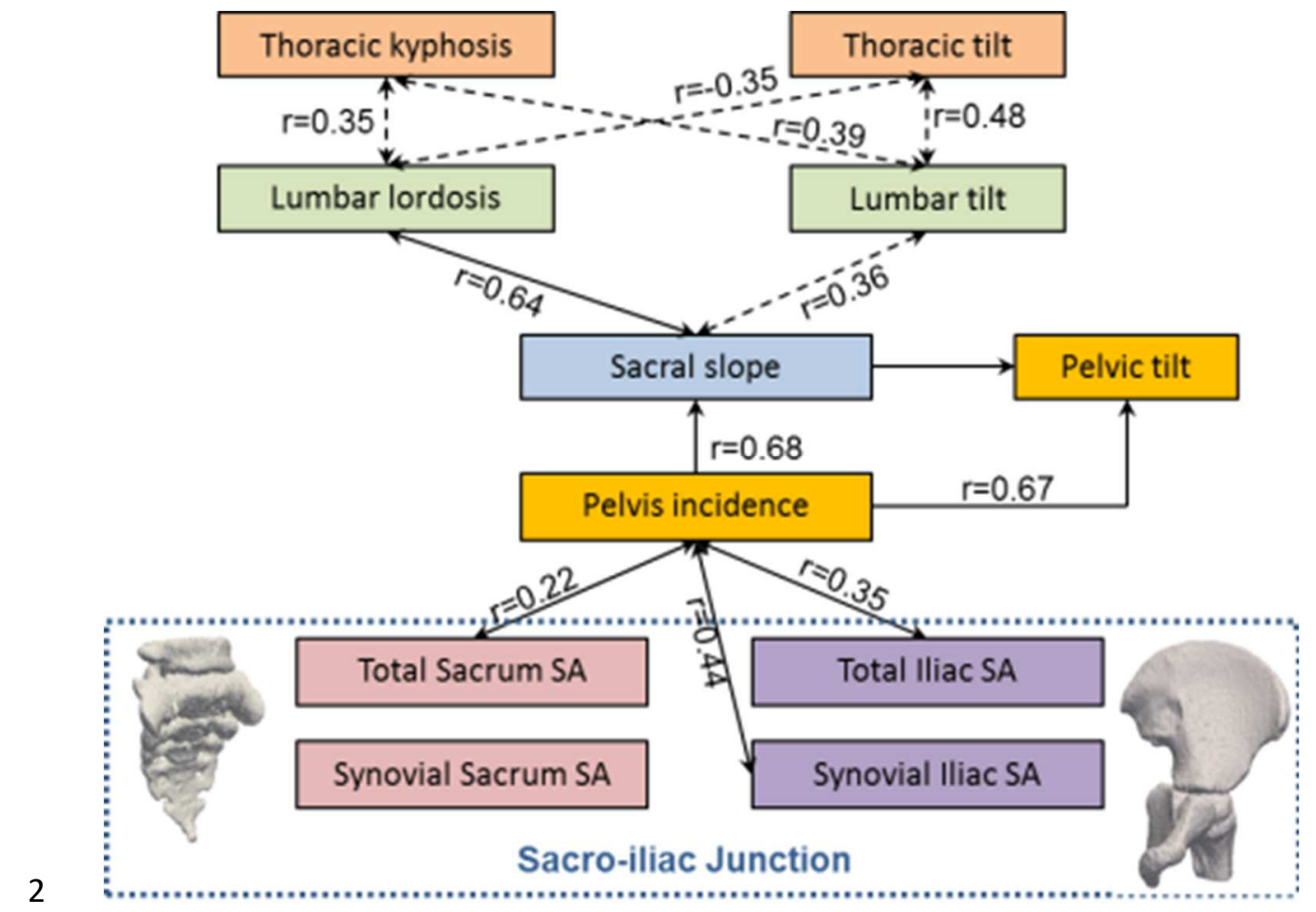

3 


\section{TABLES}

Table 1. Normal value in different growth categories ( 0 to 4 y/o, 4 to $10 \mathrm{y} / 0$ and 10 to $18 \mathrm{y} / \mathrm{o})$, in adults and in the whole population. Significativity: *: $\mathrm{p}<0.05, * *: \mathrm{p}<0.005, * * *: \mathrm{p}<0.001$

\begin{tabular}{|c|c|c|c|c|c|c|c|c|c|}
\hline Growth phases & 1 & 2 & 3 & Total & $\mathbf{p}$ & $\begin{array}{l}\text { Female } \\
\text { (gr. 1, 2 } \\
\text { and 3) }\end{array}$ & $\begin{array}{c}\text { Male } \\
\text { (gr. 1, 2 } \\
\text { and 3) }\end{array}$ & Adults & $\mathbf{p}$ \\
\hline Gender (Female) & $17(9)$ & $16(7)$ & $16(8)$ & $49(24)$ & & 24 & 25 & 20(9) & \\
\hline Age (y.) & $1.9 \pm 1$ & $6.9 \pm 1.7$ & $13.7 \pm 1.8$ & $7.4 \pm 5.1$ & & $7.5 \pm 5.4$ & $7.2 \pm 4.9$ & $27.3 \pm 5.6$ & \\
\hline Weight (Kg) & $10.9 \pm 2.4$ & $24.6 \pm 7.4$ & $47.8 \pm 6.3$ & $27.4 \pm 16.4$ & & $28.4 \pm 17.2$ & $\begin{array}{c}26.5 \pm 15 \\
9\end{array}$ & $63.7 \pm 12.1$ & \\
\hline Size (cm) & $81.5 \pm 10.3$ & $118.7 \pm 10.9$ & $156.9 \pm 7.6$ & $118.3 \pm 32.7$ & & $\begin{array}{c}118.5 \pm 34 \\
1\end{array}$ & $\begin{array}{c}118.1 \pm 31 \\
.9\end{array}$ & $170.8 \pm 11.6$ & \\
\hline BMI (Kg/m2) & $16.3 \pm 1.4$ & $17.2 \pm 2.4$ & $19.4 \pm 1.7$ & $17.6 \pm 2.2$ & & $17.7 \pm 2.5$ & $17.2 \pm 1.9$ & $21.7 \pm 2.1$ & \\
\hline BSA (m2) & $0.5 \pm 0.1$ & $0.9 \pm 0.2$ & $1.4 \pm 0.1$ & $0.9 \pm 0.4$ & & $1 \pm 0.4$ & $0.9 \pm 0.4$ & $1.7 \pm 0.2$ & \\
\hline Total Sacrum SA $\left(^{\circ}\right)$ & $31.5 \pm 8.7$ & $35.3 \pm 7.6$ & $40.5 \pm 11$ & $35.7 \pm 9.7$ & 0.22 & $35.9 \pm 10$ & $35.5 \pm 9.7$ & $34.6 \pm 9.4$ & 0.61 \\
\hline Synovial Sacrum SA $\left({ }^{\circ}\right)$ & $32.4 \pm 9.5$ & $38.2 \pm 12.1$ & $53 \pm 8.5$ & $41 \pm 13.2$ & $\begin{array}{l}<0.00 \\
1 * * *\end{array}$ & $40.9 \pm 14.7$ & $\begin{array}{c}41.1 \pm 11 \\
9\end{array}$ & $48.5 \pm 8$ & $0.035^{*}$ \\
\hline Total Iliac SA $\left({ }^{\circ}\right)$ & $42.9 \pm 7.2$ & $42.6 \pm 7.5$ & $40.4 \pm 6$ & $42 \pm 6.9$ & $0.036^{*}$ & $42.1 \pm 5.7$ & $41.9 \pm 7.9$ & $37.5 \pm 11.2$ & $0.044 *$ \\
\hline Synovial Iliac SA $\left({ }^{\circ}\right)$ & $46.2 \pm 10.5$ & $48 \pm 12.1$ & $51.3 \pm 8.6$ & $48.5 \pm 10.5$ & 0.57 & $47.7 \pm 9.9$ & $\begin{array}{c}49.2 \pm 11 \\
2\end{array}$ & $48 \pm 12.6$ & 0.78 \\
\hline Pelvic Incidence $\left(^{\circ}\right)$ & $48.3 \pm 7.9$ & $50.8 \pm 12.6$ & $49.6 \pm 7.6$ & $49.5 \pm 9.5$ & $0.027 *$ & $49.0 \pm 8.5$ & $\begin{array}{c}50.1 \pm 10 \\
4 \\
\end{array}$ & $40 \pm 13$ & $\begin{array}{l}0.002 * \\
*\end{array}$ \\
\hline
\end{tabular}

Table 2. Shape Analysis of the SIJ including area: widths and spline analysis. Significativity: *: $\mathrm{p}<0.05 .{ }^{* *}$ :p<0.005. ${ }^{* * *}: \mathrm{p}<0.001$

\begin{tabular}{|c|c|c|c|c|c|c|c|}
\hline Growth phases & 1 & 2 & 3 & Total & $\mathbf{p}$ & Adults & $\mathbf{p}$ \\
\hline Gender (Female) & 17(9) & $16(7)$ & $16(8)$ & $49(24)$ & & $20(9)$ & \\
\hline $\operatorname{Age}\left(y_{.}\right)$ & $1.9 \pm 1$ & $6.9 \pm 1.7$ & $13.7 \pm 1.8$ & $7.4 \pm 5.1$ & & $27.3 \pm 5.6$ & \\
\hline
\end{tabular}


Total Sacrum SA area $\left(\mathrm{cm}^{2}\right)$

Synovial Sacrum SA area $\left(\mathrm{cm}^{2}\right)$

Synovial/Total sacrum ratio

Total iliac area $\left(\mathrm{cm}^{2}\right)$

Synovial iliac area $\left(\mathrm{cm}^{2}\right)$

Synovial/Total iliac ratio

Sacrum long width (mm)

Sacrum cumulative width (mm)

Sacrum average width $(\mathrm{mm})$

Iliac long width (mm)

Iliac cumulative width (mm)

Iliac average width $(\mathrm{mm})$

\begin{tabular}{|c|c|c|c|c|c|c|}
\hline $2.19 \pm 0.78$ & $5.59 \pm 1.16$ & $9.26 \pm 2.37$ & $5.7 \pm 3.22$ & $<0.001 * * *$ & $9.86 \pm 3.5$ & $0.003 * *$ \\
\hline $1.36 \pm 0.67$ & $3.63 \pm 0.85$ & $5.9 \pm 1.66$ & $3.64 \pm 2.14$ & $<0.001 * * *$ & $6.69 \pm 2$ & $0.009 * *$ \\
\hline $0.7 \pm 0.06$ & $0.71 \pm 0.06$ & $0.7 \pm 0.04$ & $0.71 \pm 0.05$ & $0.048^{*}$ & $0.66 \pm 0.1$ & 0.061 \\
\hline $2.43 \pm 0.85$ & $5.8 \pm 1.84$ & $9.47 \pm 2.28$ & $5.9 \pm 3.32$ & $<0.001 * * *$ & $9.17 \pm 3.85$ & $<0.001 * * *$ \\
\hline $1.72 \pm 0.66$ & $4.02 \pm 0.95$ & $6.6 \pm 1.64$ & $4.13 \pm 2.26$ & $<0.001 * * *$ & $6 \pm 2.27$ & $<0.001 * * *$ \\
\hline $0.6 \pm 0.16$ & $0.65 \pm 0.07$ & $0.64 \pm 0.06$ & $0.63 \pm 0.11$ & $0.006 * *$ & $0.7 \pm 0.05$ & $0.011 *$ \\
\hline $25.7 \pm 8.2$ & $42.1 \pm 8.1$ & $55.4 \pm 6.8$ & $41.3 \pm 14$ & $<0.001 * * *$ & $50.8 \pm 11.6$ & $0.011 *$ \\
\hline $61.4 \pm 18$ & $103.5 \pm 26.8$ & $147.8 \pm 27.1$ & $104.9 \pm 41.8$ & $<0.001 * * *$ & $117.8 \pm 37.6$ & 0.24 \\
\hline $14.5 \pm 3.2$ & $23.8 \pm 14.5$ & $34.8 \pm 17.2$ & $24.6 \pm 15.2$ & $<0.001 * * *$ & $45 \pm 13.8$ & $<0.001 * * *$ \\
\hline $20.3 \pm 3.1$ & $34.6 \pm 6.6$ & $49.4 \pm 5.4$ & $34.8 \pm 12.8$ & $<0.001 * * *$ & $47.2 \pm 10.3$ & $<0.001 * * *$ \\
\hline $70.9 \pm 15.2$ & $104.8 \pm 25.2$ & $152.7 \pm 24.4$ & $109 \pm 39.8$ & $<0.001 * * *$ & $125.1 \pm 35.9$ & 0.13 \\
\hline $13.9 \pm 4.1$ & $22.2 \pm 10.1$ & $36 \pm 17.1$ & $24.2 \pm 14.5$ & $<0.001 * * *$ & $42.8 \pm 10.5$ & $<0.001 * * *$ \\
\hline
\end{tabular}


Table 3. Pearson correlations between SIJ characteristics and age or PI.

\begin{tabular}{lcc} 
& $\begin{array}{c}\text { Correlations with age } \\
\mathbf{r}(\mathbf{p})\end{array}$ & $\begin{array}{c}\text { Correlations with PI } \\
\mathbf{r}(\mathbf{p})\end{array}$ \\
\hline Total Sacrum SA $\left(^{\circ}\right)$ & $0.01(0.6)$ & $0.22(0.04)^{*}$ \\
Synovial Sacrum SA $\left(^{\circ}\right)$ & $0.47(<0.001)^{* * *}$ & $0.21(0.4)$ \\
Total Iliac SA $\left(^{\circ}\right)$ & $0.24(0.03)^{*}$ & $0.35(0.002)^{* *}$ \\
Synovial Iliac SA $\left({ }^{\circ}\right)$ & $0.35(0.63)$ & $0.44(<0.001)^{* * *}$ \\
\hline Total Sacrum SA area $(\mathbf{m m 2})$ & $0.72(<0.001)^{* * *}$ & $0.22(0.11)$ \\
Synovial Sacrum SA area $(\mathbf{m m} 2)$ & $0.75(<0.001)^{* * *}$ & $0.21(0.046)^{*}$ \\
Total Iliac SA area $(\mathbf{m m 2})$ & $0.63(<0.001)^{* * *}$ & $0.15(0.36)$ \\
Synovial Iliac SA area $(\mathbf{m m})$ & $0.61(<0.001)^{* * *}$ & $0.15(0.34)$ \\
\hline Sacrum long width $(\mathbf{m m})$ & $0.61(<0.001)^{* * *}$ & $0.1(0.35)$ \\
Sacrum cumulative width $(\mathbf{m m})$ & $0.46(<0.001)^{* * *}$ & $0.14(0.88)$ \\
Sacrum average width $(\mathbf{m m})$ & $0.61(<0.001)^{* * *}$ & $0.29(0.01)^{*}$ \\
Iliac long width $(\mathbf{m m})$ & $0.7(<0.001)^{* * *}$ & $0.23(0.44)$ \\
Iliac cumulative width $(\mathbf{m m})$ & $0.53(<0.001)^{* * *}$ & $0.14(0.85)$ \\
Iliac average width $(\mathbf{m m})$ & $0.64(<0.001)^{* * *}$ & $0.75(0.058)$ \\
\hline
\end{tabular}

